\title{
The effect of chemical activators on early strength of ordinary Portland cement-slag mortars
}

\author{
Fathollah Sajedi , Hashim Abdul Razak
}

More than 167 million tons of slag was produced worldwide in 1996 [1]. Ground granulated blast furnace slag (GGBFS) is a low performance cementitious material, which can achieve high compression strength when an alkaline activator is used. However, Glukhovsky [2] had already made crucial investigations about the activation of GGBFS. This author [3] classified alkaline activators in six groups; where $M$ is an alkaline:

(a) Caustic alkalis, MOH.

(b) Non-silicate weak acid salts: $\mathrm{M}_{2} \mathrm{CO}_{3}, \mathrm{M}_{2} \mathrm{SO}_{3}, \mathrm{M}_{3} \mathrm{PO}_{4}$, MF, etc.

(c) Silicates, $\mathrm{M}_{2} \mathrm{O} \_\mathrm{nSiO}$.

(d) Aluminates, $\mathrm{M}_{2} \mathrm{O}_{-} \mathrm{nAl}_{2} \mathrm{O}_{3}$.

(e) Aluminosilicates, $\mathrm{M}_{2} \mathrm{O}_{-} \mathrm{Al}_{2} \mathrm{O}_{3} \_(2-6) \mathrm{SiO}_{2}$.

(f) Non-silicate strong acid salts, $\mathrm{M}_{2} \mathrm{SO}_{4}[4,5]$.

Of all these activators, $\mathrm{NaOH}, \mathrm{Na}_{2} \mathrm{CO}_{3}, \mathrm{Na}_{2} \mathrm{O} \_\mathrm{nSiO} 2$ and $\mathrm{Na}_{2} \mathrm{SO}_{4}$ are the most widely available and economical chemicals. Some potassium compounds have been used in laboratory studies. However, their potential applications will be very limited due to their availability and costs. Conversely, the properties of sodium and potassium compounds are very similar.

Hydration products are responsible for attained strength, while pores have a negative effect on strength. The strength of cement and concrete materials is perhaps the most important overall measure of quality, although other properties may also be critical. For alkali-activated slag cement, the following are the main factors determining the strength of cement pastes and mortars [2,5]:

_ The nature of slag and activators.

_ Dosage of activators.

_ Curing temperature.

_Water/slag ratio.

_ Fineness of slag.

_ Timing of the addition of activators.

_ Other additives.

_ The modulus ratio of solution.

_ Compaction pressure for systems with very low water/slag 
ratio.

When the water/slag ratio is high, the initial porosity of the system

is determined by the water/slag ratio. However, if the water/

slag ratio is low, compaction pressure will determine the initial

porosity of the system $[5,6]$.

GGBFS is a by-product of the iron making process and is produced

by water quenching of molten blast furnace slag. For its

use in mortars, concretes and blended cements, it must be ground

to improve its reactivity during cement hydration. The main

constituents of $\mathrm{GGBFS}$ are $\mathrm{CaO}, \mathrm{SiO}_{2}, \mathrm{Al}_{2} \mathrm{O}_{3}$ and $\mathrm{MgO}$. Slag shows

primarily cementitious behavior but may also show some pozzolanic character (reaction with lime). The use of GGBFS as cement replacement in mortar and concrete is a common practice due to the technological and environmental benefits. Replacement of clinker by slag, not only offers energy savings and cost reduction compared to ordinary Portland cement (OPC), but also other advantages such as a lower heat of hydration, high sulfate and acid resistance, better workability, and good ultimate strength and durability. Attempts have been made to overcome the problem of slow strength development in Portland slag cement [7]. The problem of low early strength can be overcome by using an alkali-activated slag (SSA) as the type of binder, which can potentially yield early high-strength concrete [8]. This paper discusses the increase of strengths at early days, by using three types of activators.

2. Hydration mechanism of OPC

Since hydration starts at the surface of the cement particles, it is the total surface area of cement that represents the material available for hydration. Thus, the rate of hydration depends on the fineness of cement particles, and for a rapid development of strength a high fineness is necessary. However, the cost of grinding and the effect of fineness on other properties, e.g. gypsum requirement, workability of fresh concrete and long term behavior must be borne in mind [9].

Portland cement is the most commonly used material in the worldwide construction industry. It has a high level of $\mathrm{CO}_{2}$ (one ton of cement generates one ton of $\mathrm{CO}_{2}$ ) and its uses tend to become less competitive compared to newer, alternative ecological binders, like geopolymers [10]. The use of GGBFS to replace part of the Portland cement in traditional concrete has been shown to have a beneficial effect on durability. Moreover, if part of the Portland cement can be replaced by waste materials, the amount of cement needed and therefore the amount of $\mathrm{CO}_{2}$ released into the atmosphere can be reduced. The two principal products of Portland cement hydration are crystalline portlandite $\mathrm{Ca}(\mathrm{OH})_{2}$ and an amorphous 
material known as C-S-H gel. Since the chemical composition of Portland cement does not change significantly from source to source, it is generally accepted that fully hydrated Portland cement consists of $70 \%$ calcium silicate hydrate (C-S-H), $20 \%$ calcium hydroxide $(\mathrm{Ca}(\mathrm{OH})), 7 \%$ calcium sulphoaluminate hydrates and $3 \%$ anhydrate cement particles. C-S-H is not a well-defined compound and its $\mathrm{C} / \mathrm{S}$ ratio varies with the composition of the cement and hydration conditions. Several models have been proposed to describe C-S-H. Details on these models can be found in Ref. [5].

3. Hydration mechanism of GGBFS

The hydration mechanism of GGBFS is different from that of cement.

When GGBFS is mixed with water, initial hydration is much slower than OPC mixed with water. Hydration of GGBFS in the presence of OPC depends upon the breakdown and dissolution of the glassy slag structure by hydroxyl ions released during the hydration of OPC and also the alkali content in cement. The hydration of GGBFS consumes calcium hydroxide and uses it for additional CSH formation. Research by Regourd [11], Vanden Bosch [12], Roy and Idorn [13] has suggested that, in general, the hydration of GGBFS in combination with OPC, at normal stage, is a two-stage reaction. Initially, and during the early hydration, the predominant reaction is with alkali hydroxide, but subsequent reactions are predominantly with calcium hydroxide [3]. The hydration and hardening step of slag cement can be described as follows:

Firstly, C-S-H gel and ettringite form from hydration of clinker minerals and release $\mathrm{Ca}(\mathrm{OH})_{2}$. This $\mathrm{Ca}(\mathrm{OH})_{2}$ not only maintains a certain value of $\mathrm{pH}$ in the solution to activate the hydration of slag, but also reacts with all ions of slag separation to form the new hydration products [14].

From a chemical standpoint, slags can be classified into two

types according to their basicity index. The simplest one being the C/S ratio given by Nkinamubanzi [15]. The conditions for reactivity of slag are as follows [9]:

Full text available at :

http://www.sciencedirect.com/science/article/pii/S0950061810001261

http://ac.els-cdn.com/S0950061810001261/1-s2.0-S0950061810001261-main.pdf?_tid=037aee7a-7820-11e391fd-00000aab0f26\&acdnat $=1389156644$ 0a6299272577efa3436bc0823103770b 